Dementia

and Geriatric

Cognitive Disorders
Dement Geriatr Cogn Disord 2006;21:170-174

DOI: $\underline{10.1159 / 000090699}$
Accepted: September 28, 2005

Published online: January 3, 2006

\title{
Unique Contribution of Family Functioning in Caregivers of Patients with Mild to Moderate Dementia
}

\author{
Geoffrey Tremont Jennifer Duncan Davis Duane S. Bishop \\ Department of Psychiatry and Human Behavior, Brown Medical School, and Department of Psychiatry, \\ Rhode Island Hospital, Providence, R.I., USA
}

\section{Key Words}

Dementia caregivers - Caregiver burden · Family functioning

\begin{abstract}
The relationship between family functioning and dementia caregiving is complex. The present study examined the interrelationships between family functioning, caregiver burden, and patient characteristics. Participants were 72 live-in, family caregivers of patients with mild $(n=47)$ or moderate dementia $(n=25)$. Caregivers completed measures of burden, family functioning, depression, and anxiety. Ratings of patients' memory/behavior problems and patients' activities of daily living were also collected. Results indicated that higher levels of caregiver burden were significantly associated with increased caregiver depression and anxiety, greater frequency of memory and behavior problems in the dementia patient, worse activities of daily living, and poorer family functioning. Even after controlling for caregiver depression, caregiver anxiety, and frequency of memory/behavior problems in dementia patients, poorer family functioning continued to be associated with higher levels of caregiver burden. Caregivers with high levels of burden reported greater family dysfunction in communication and roles, regardless of their relationship to the patient (i.e., spouse or child). These findings suggest that including
\end{abstract}

a family systems component in caregiver interventions may be beneficial in reducing burden in these very distressed individuals.

Copyright $(2006$ S. Karger AG, Basel

\section{Introduction}

Caregiver burden in dementia is known to negatively affect physical and emotional health, although little is known about how family functioning is affected. Several studies have examined the impact of family characteristics on burden and emotional distress in dementia caregivers. For example, criticism and emotional overinvolvement expressed by the family member toward the patient (i.e., expressed emotion) are associated with increased depression, greater burden, and fewer positive benefits from caregiving [1]. Low family cohesiveness, high family conflict, too rigid or too permeable family boundaries, low levels of family organization, lack of clear communication, and poor spousal support have also been associated with poor response to chronic disease such as dementia [2]. Primary caregivers who receive support from other family members experience lower levels of caregiver strain [3, 4]. Strawbridge and Wallhagen [5] found strong positive correlations between family conflict and caregiver burden and self-reported health. In contrast, several studies have found that families who use

\section{KARGER \\ Fax +4161306 1234 E-Mail karger@karger.ch} www.karger.com
(C) 2006 S. Karger AG, Basel $1420-8008 / 06 / 0213-0170 \$ 23.50 / 0$

Accessible online at:

www.karger.com/dem
Geoffrey Tremont, $\mathrm{PhD}$

Neuropsychology Program, Physicians Office Building, Suite 430

Rhode Island Hospital, 593 Eddy Street

Providence, RI 02903 (USA)

Tel. +1 401444 4500, Fax +1 401444 6643, E-Mail gtremont@lifespan.org 
mechanisms to avoid family conflict and instead use guilt tend to show declines in self-reported health, increased caregiving distress, and less follow through with treatment recommendations than families without these characteristics [6]. There is also evidence that families of dementia patients who use a focused decision making style, positive conflict resolution methods, and focus on a primary caregiver provide significantly more help to the patient than those families who do not use this type of an approach or try to divide resolution of the problem among family members [7]. Although these studies have identified family characteristics associated with dementia caregiving, none of the studies has examined the functioning of the family unit as a system.

Recently, Heru et al. [8] found that perceived family dysfunction was associated with increases in self-reported caregiver strain and burden in 38 dementia caregivers. This was the first study to use the Family Assessment Device (FAD), a psychometrically sound measure of family functioning based on the McMaster model of family functioning [9]. The present study examined the interrelationships between family functioning, caregiver burden, and patient characteristics in a sample of live-in, family caregivers of individuals with dementia. Given the complex construct of burden, our aim was to understand the unique contribution of family functioning as well as to consider other variables that could explain some of these relationships.

\section{Method}

\section{Participants and Procedure}

The participants were 72 caregivers of patients with dementia who completed baseline assessment measures as part of a caregiver intervention study. Caregivers were recruited from memory disorder clinics, support groups, and newspaper/television advertisements in the Providence, Rhode Island region. All caregivers resided with the care recipient and were providing a minimum of $4 \mathrm{~h}$ of daily care over at least 6 months. The majority of caregivers were female $(n=56 ; 77 \%)$ and Caucasian $(n=69 ; 96 \%)$. Sixty-one percent $(n=44)$ were spouses, and the remaining caregivers were adult children. Caregivers had been providing care for an average of 39.68 months ( $\mathrm{SD}=35.57)$, and the average length of dementia diagnosis was 39.71 months $(\mathrm{SD}=35.90)$. Caregivers' average age was $64.36(\mathrm{SD}=11.66)$ and care recipients' average age was 77.18 $(\mathrm{SD}=9.47)$. Care recipient's diagnosis of dementia was confirmed by their primary physicians. Etiology of dementia in the care recipient included probable Alzheimer's disease $(n=42)$, vascular dementia $(n=4)$, mixed dementia $(n=4)$, frontotemporal dementia $(n=5)$, dementia with Lewy bodies $(n=4)$, Parkinson's dementia $(\mathrm{n}=3)$, hydrocephalus $(\mathrm{n}=2)$, progressive supranuclear palsy $(n=1)$, dementia NOS $(n=2)$, and unknown $(n=5)$. Dementia severity was determined by the Clinical Dementia Rating Scale
[10]. In addition to global scores, sums of box scores were also calculated by summing ratings from each category. Caregivers completed the following measures as part of a baseline assessment of a large-scale intervention study: Geriatric Depression Scale [11], Activities of Daily Living (ADL) [12], Revised Memory and Behavior Problems Checklist [13], Dementia Knowledge Test [14], StateTrait Anxiety Inventory (State Form) [15], and the Zarit Burden Interview [4]. Caregivers also completed the FAD [9]. The FAD is a 60-item self-report questionnaire designed to assess the six dimensions of the McMaster Model of Family Functioning, including problem-solving, communication, roles, affective responsiveness, affective involvement, behavioral control, and general functioning. Psychometric properties of the scale support its reliability and validity in psychiatric, medical, and nonclinical samples [16]. Caregivers were asked to rate statements about their families along a 4-point Likert Scale from strongly disagree to strongly agree. It was emphasized to caregivers to answer according to their perceptions of their family.

\section{Results}

Intercorrelations between all measures are presented in table 1 . As can be seen, perceived burden was moderately correlated with caregiver depression and anxiety, frequency of patient behavior problems, and family functioning. Weaker relationships were seen between burden and severity of dementia (i.e., sum of boxes), length of diagnosis, dementia knowledge, length of caregiving, and total ADL, although this latter variable was statistically significant. Interestingly, family functioning was significantly related to caregiver depression and caregiver situational anxiety. Length of caregiving, caregivers' knowledge of dementia, and length of diagnosis were not related to caregiver distress measures or family functioning. Patient ADL were significantly related to caregiver depression. To examine the unique contribution of family functioning to burden, a partial correlation between family functioning and burden removing the variance associated with caregiver depression, anxiety, and frequency of memory and behavior problems in the patient was calculated. Findings showed a statistically significant relationship, even after controlling for possible contributing variables $(r=0.24, p=0.04)$.

To examine which aspects of family functioning are the most important contributors to the relationship with burden, caregivers were divided into low vs. high burden groups based on a cut-off score on the Zarit Burden Interview (high $=$ a score of $\geq 35$ ). Because relationship type (spouse vs. child) could potentially impact family functioning, we conducted burden (high vs. low) by caregiver relationship (spouse vs. child) analysis of variance. None of the interactions between relationship type and burden 
Table 1. Intercorrelations between outcome measures

\begin{tabular}{|c|c|c|c|c|c|c|c|c|c|}
\hline & GDS & ADL & $\begin{array}{l}\text { Sum of } \\
\text { boxes }\end{array}$ & $\begin{array}{l}\text { Length of } \\
\text { diagnosis }\end{array}$ & MBPC & STAI & DKT & FAD & $\begin{array}{l}\text { Length } \\
\text { of care }\end{array}$ \\
\hline ZBI & $0.40 * *$ & $-0.28^{*}$ & 0.21 & 0.08 & $0.47 * *$ & $0.34 * *$ & 0.12 & $0.42 * *$ & 0.09 \\
\hline GDS & - & $-0.34 * *$ & $0.24^{*}$ & 0.05 & 0.17 & $0.57 * *$ & -0.11 & $0.40 * *$ & 0.05 \\
\hline ADL & & - & $-0.76 * *$ & $-0.34 * *$ & 0.01 & -0.04 & -0.10 & -0.16 & -0.22 \\
\hline Sum of boxes & & & - & $0.38 * *$ & 0.09 & -0.05 & 0.15 & 0.01 & $0.24^{*}$ \\
\hline Length of diagnosis & & & & - & 0.15 & -0.02 & 0.14 & 0.15 & $0.52 * *$ \\
\hline MBPC & & & & & - & 0.11 & 0.09 & 0.15 & -0.06 \\
\hline STAI & & & & & & - & -0.20 & $0.57 * *$ & 0.11 \\
\hline DKT & & & & & & & - & -0.15 & 0.14 \\
\hline FAD & & & & & & & & - & 0.14 \\
\hline
\end{tabular}

ZBI = Zarit Burden Interview; GDS = Geriatric Depression Scale; ADL = Activities of Daily Living; MBPC = Memory and Behavior Problem Checklist; STAI = State Trait Anxiety Inventory; DKT = Dementia Knowledge Test; FAD = Family Assessment Device - General Functioning Subscale.

$* * \mathrm{p}<0.01, * \mathrm{p}<0.05$.

Table 2. Mean FAD scores for caregivers reporting high versus low burden (mean $\pm \mathrm{SD})$

\begin{tabular}{lllll}
\hline & $\begin{array}{l}\text { Low burden } \\
(\mathrm{n}=40)\end{array}$ & $\begin{array}{l}\text { High burden } \\
(\mathrm{n}=32)\end{array}$ & $\mathrm{F}$ & $\mathrm{p}$ \\
\hline Problem solving & $1.90 \pm 0.38$ & $2.09 \pm 0.48$ & 1.75 & 0.190 \\
Communication & $2.07 \pm 0.40$ & $2.36 \pm 0.38$ & 9.53 & 0.003 \\
Roles & $2.00 \pm 0.41$ & $2.30 \pm 0.39$ & 7.06 & 0.010 \\
Affective responsiveness & $1.92 \pm 0.50$ & $2.23 \pm 0.56$ & 5.07 & 0.028 \\
Affective involvement & $1.82 \pm 0.48$ & $2.08 \pm 0.32$ & 3.91 & 0.052 \\
Behavioral control & $1.71 \pm 0.40$ & $1.93 \pm 0.38$ & 5.70 & 0.020 \\
General functioning & $1.82 \pm 0.47$ & $2.15 \pm 0.51$ & 5.23 & 0.025 \\
\hline
\end{tabular}

Higher FAD scores indicate greater dysfunction. Low burden $\leq 34$ and high burden $\geq 35$ on Zarit Burden Interview. for any of the FAD subscale scores was significant. Furthermore, no significant main effects were found for relationship type for any of the FAD subscale scores, arguing against a significant effect of relationship type on family functioning. Average FAD subscale scores for the burden main effect are presented in table 2. Based on published clinical cut-off scores [17], the high burden group shows dysfunctional scores in communication, roles, affective responsiveness, behavior control and general functioning domains. FAD scores for the low burden group were all within normal limits. To minimize the risk of type I error, only group differences significant at $\mathrm{p}<0.01$ were interpreted. As can be seen in table 2, FAD subscales of communication and roles were significantly higher (indicating greater dysfunction) in caregivers with high burden compared to those reporting low burden scores.

\section{Discussion}

Results of this study show that family functioning is a significant contributor to perceptions of burden among a group of live-in dementia caregivers who met strict inclusion criteria. After removing the variance associated with caregiver depression and anxiety and patient behavior problems, a significant relationship between family functioning and burden was still found, providing support for the unique contribution of family functioning to caregiver burden. In addition, strong relationships were seen between poor family functioning and caregiver depression and anxiety. Aspects of family functioning have been shown to be dysfunctional in psychiatric disorders [16, 18], although our study is one of the few to demonstrate these relationships in dementia caregivers. Compared to 
previous studies of medical and psychiatric samples, our dementia caregivers exhibited FAD subscale scores that were somewhat worse than medical patients and better than psychiatric samples, particularly for the problemsolving, communication, and general functioning subscales [16]. These findings suggest that dementia caregivers should be assessed for family difficulties within these domains.

Our findings are consistent with those of Heru et al. [8] as well as other studies showing a relationship between family characteristics and dementia caregiver burden. We add to results of previous studies by controlling for moderating variables (e.g., depression, anxiety, patient behavior problems), including measures of clinically-rated dementia severity, and including a more homogenous group of caregivers (i.e., those residing with the patient). Obviously, our findings do not address the direction of the relationship. That is, whether family dysfunction results in greater caregiver burden or whether increased burden causes greater family dysfunction. Studying family functioning (and associated moderating variables) in a longitudinal study may be more likely to identify causal relationships. Regardless of the direction, our findings highlight the importance of including a family assessment and intervention when working with dementia caregivers.

Zero-order correlations between burden and other caregiver and patient variables revealed significant relationships between burden and caregivers' emotional function. In addition, a strong relationship was seen between burden and frequency of memory and behavior problems in the patient. These findings highlight the complexity of caregiver burden as a construct and argue for identification of its unique contributors. After conducting a meta-analysis of dementia caregiving interventions, Acton and Kang [19] concluded that burden was potentially too global an outcome, and they called for use of precise measures of caregivers' functioning. Our findings support the inclusion of family functioning as an important outcome measure in caregiver intervention studies.

Interestingly, we found that family functioning was only weakly related to measures of patient functioning, including severity of dementia, length of diagnosis, ADL, and frequency of memory and behavior problems. Others have found that subjective caregiver perceptions of problems, satisfaction with and amount of social support, available resources, coping skills, and feelings of self-efficacy are important predictors of caregiver depression and stress [20, 21]. Similarly, there is evidence that subjective caregiver factors may be more important than patient factors to the prediction of nursing home placement $[22,23]$.
Caregivers who were high in burden reported several areas of family dysfunction that distinguished them from those caregivers low in burden. We found that burden was associated with perceived ineffective communication among family members. In addition, caregivers who were burdened described difficulty with distribution and follow-through of family tasks. It is possible that these findings reflect the changing role of patient with dementia in the family. It is equally plausible that our findings reflect the turmoil that can be created when there is disagreement among family members about how to manage and care for a family member with dementia. It is quite common for caregivers (especially live-in caregivers) to describe that other family members do not fully appreciate either the level of care necessary or the stress and burden associated with providing care. Our results suggest that family therapy or supportive strategies early in the caregiving process may reduce the risk for subsequent caregiver burden. For example, family members may need encouragement and support to express their feelings and thoughts about the disease, as well as assistance in specifying roles of family members and specific task assignment.

As noted above, the cross-sectional nature of the current study is a limitation. In addition, our sample size did not allow for subgroup analyses of burden and family functioning in dementia subtypes. There are clinical reasons to believe that frontotemporal dementia and dementia with Lewy bodies may be associated with different levels of caregiver burden.

Overall, findings from the present study support the unique contribution of family functioning to dementia caregiver burden. The study establishes empirical support for the use of family assessment and family-based treatments when working with dementia caregivers. Emphasizing the role of family functioning in these caregivers may ultimately lead to reduced burden and its associated negative consequences.

\section{Acknowledgments}

This research was conducted with support from the National Institute of Mental Health (MH62561). The authors wish to thank Colleen Slavin, Pamela Steadman, and Margaret Trippell for assistance with data collection. 


\section{References}

-1 Wagner AW, Logsdon RG, Pearson JL, Teri L: Caregiver expressed emotion and depression in Alzheimer's disease. Aging Ment Health 1997; 1:132-139.

-2 Fisher L, Nakell LC, Terry HE, Ransom DC: The California Family Health Project. III. Couple emotional management and adult health. Fam Process 1992;31:269-287.

$\checkmark 3$ Horowitz A: Sons and daughters as caregivers to older parents: differences in role performances and consequences. Gerontologist 1985;25:612-617.

4 Zarit SH, Reever KE, Bach-Peterson J: Relatives of impaired elderly: correlates of feelings of burden. Gerontologist 1980;20:649-655.

5 Strawbridge WJ, Wallhagen MI: Impact of family conflict on adult child caregivers. Gerontologist 1991;31:770-777.

-6 Fisher L, Lieberman MA: The effects of family context on adult offspring of patients with Alzheimer's disease: a longitudinal study. J Fam Psychol 1996;10:180-191.

7 Lieberman MA, Fisher L: The effects of family conflict resolution and decision making on the provision of help for an elder with Alzheimer's disease. Gerontologist 1999;39:159-166.

$>8$ Heru AM, Ryan CE, Iqbal A: Family functioning in the caregivers of patients with dementia. Int J Geriatr Psychiatry 2004;19:533-537. -9pstein N, Baldwin L, Bishop D: The McMaster Family Assessment Device. J Marital Fam Ther 1983;9:171-180.

10 Hughes CP, Berg L, Danziger WL, Coben LA, Martin RL: A new clinical scale for the staging of dementia. Br J Psychiatry 1982;140:566572.

11 Yesavage JA, Brink TL, Rose TL, Lum O, Huang V, Adey M, Leirer VO: Development and validation of a geriatric depression screening scale: a preliminary report. J Psychiatr Res 1983;17:37-49.

12 Lawton MP, Brody EM: Assessment of older people. Self-maintaining and instrumental activities of daily living. Gerontologist 1969; 179-188.

$>13$ Teri L, Truax P, Logsdon R, Uomoto J, Zarit S, Vitaliano PP: Assessment of behavioral problems in dementia: The Revised Memory and Behavior Problems Checklist. Psychol Aging 1992; 7:622-631.

14 Dieckmann L, Zarit SH, Zarit JM, Gatz M: The Alzheimer's disease knowledge test. Gerontologist 1988;28:402-407.

15 Spielberger CD, Gorsuch RL, Kushene RE: Manual for the State-Trait Anxiety Inventory. Palo Alto, Consulting Psychologists Press, 1971.

16 Kabacoff R, Miller I, Epstein N, Bishop D, Keitner G: A psychometric study of the McMaster Family Assessment Device in psychiatric, medical, and nonclinical samples. J Fam Psychol 1990;3:431-439.
17 Miller IW, Epstein NB, Bishop DS, Keitner GI: The McMaster Family Assessment Device: reliability and validity. J Marit Fam Ther 1985; 11:345-356.

18 Friedmann MS, McDermut WH, Solomon DA, Ryan CE, Keitner GI, Miller IW: Family functioning and mental illness: a comparison of psychiatric and nonclinical families. Fam Process 1997;36:357-367.

19 Acton GJ, Kang J: Interventions to reduce the burden of caregiving for an adult with dementia: a meta-analysis. Res Nurs Health 2001;24: 349-360.

20 Kosloski K, Young RF, Montgomery RJV: A new direction for intervention with depressed caregivers to Alzheimer's patients. Fam Relat 1999;48:373-379.

21 Coen RF, Swanwick GR, O’Boyle CA, Coakley $\mathrm{D}$ : Behaviour disturbance and other predictors of carer burden in Alzheimer's disease. Int J Geriatr Psychiatry 1997; 12:331-336.

Geriatr Psychiatry 1997; $12: 331-336$.
Black W, Almeida OP: A systematic review of the association between the behavioral and psychological symptoms of dementia and burden of care. Int Psychogeriatr 2004;16:295315 .

23 Gaugler JE, Kane RL, Kane RA, Clay T, Newcomer R: Caregiving and institutionalization of cognitively impaired older people: utilizing dynamic predictors of change. Gerontologist 2003;43:219-229. 